\title{
Sliceable Transponders for Metro-Access Transmission Links
}

\author{
Wagner, Christoph; Madsen, P.; Spolitis, S.; Vegas Olmos, Juan José; Tafur Monroy, Idelfonso
}

\section{Published in:}

Proceedings of SPIE

Link to article, DOI:

$10.1117 / 12.2079079$

Publication date:

2015

Document Version

Publisher's PDF, also known as Version of record

Link back to DTU Orbit

Citation (APA):

Wagner, C., Madsen, P., Spolitis, S., Vegas Olmos, J. J., \& Tafur Monroy, I. (2015). Sliceable Transponders for Metro-Access Transmission Links. In A. K. Srivastava, B. B. Dingel, \& A. K. Dutta (Eds.), Proceedings of SPIE (Vol. 9388). [938805] SPIE - International Society for Optical Engineering. Proceedings of SPIE - The International Society for Optical Engineering https://doi.org/10.1117/12.2079079

\section{General rights}

Copyright and moral rights for the publications made accessible in the public portal are retained by the authors and/or other copyright owners and it is a condition of accessing publications that users recognise and abide by the legal requirements associated with these rights.

- Users may download and print one copy of any publication from the public portal for the purpose of private study or research.

- You may not further distribute the material or use it for any profit-making activity or commercial gain

- You may freely distribute the URL identifying the publication in the public portal 


\title{
Sliceable Transponders for Metro-Access Transmission Links
}

\author{
C. Wagner ${ }^{* a}$, P. Madsen ${ }^{\mathrm{a}}$, S. Spolitis ${ }^{\mathrm{b}}$, J. J. Vegas Olmos ${ }^{\mathrm{a}}$, I. Tafur Monroy ${ }^{\mathrm{a}}$ \\ ${ }^{a}$ DTU Fotonik, Technical University of Denmark, Build. 343, Ørsteds Plads, Lyngby, DK 2800; \\ ${ }^{\mathrm{b}}$ Institute of Telecommunications, Riga Technical University, Azenes street 12, Riga, LV-1048
}

\begin{abstract}
This paper presents a solution for upgrading optical access networks by reusing existing electronics or optical equipment: sliceable transponders using signal spectrum slicing and stitching back method after direct detection. This technique allows transmission of wide bandwidth signals from the service provider (OLT - optical line terminal) to the end user (ONU - optical network unit) over an optical distribution network (ODN) via low bandwidth equipment. We show simulation and experimental results for duobinary signaling of $1 \mathrm{Gbit} / \mathrm{s}$ and $10 \mathrm{Gbit} / \mathrm{s}$ waveforms. The number of slices is adjusted to match the lowest analog bandwidth of used electrical devices and scale from 2 slices to 10 slices. Results of experimental transmission show error free signal recovery by using post forward error correction with $7 \%$ overhead.
\end{abstract}

Keywords: signal slicing, duobinary, optical access networks, digital signal processing

\section{INTRODUCTION}

Internet traffic from end users grows faster than ever. Main reasons for the increasing demand of the end users are, for example, e-health systems, video conferences and cloud computing. Network operators face several challenges in design, deployment and maintenance, and have to cope with the increased bandwidth demand. Usual solutions for network upgrades are cost intensive, like using more wavelengths or wider bandwidth electronics and optical equipment. These are the key drivers for researching in new techniques to overcome the electronic bottleneck, which is one of the main challenges, currently. Simultaneously, new optical transponders should have a variable bandwidth and be able to change the modulation format adaptively.

Sliceable transponders are another solution for network upgrades and were introduced for coherent systems by Geisler et al. [1-3]. These sliceable transponders were based on a frequency comb and In-phase and Quadrature-phase (I/Q)-MachZehnder modulators (MZM). Geisler et al. proposed sliceable transponders for matching the electronic and optical bandwidth. Furthermore, they achieved to change the modulation format adaptively to successful transmit under varying transmission conditions of a link.

However, coherent transmission systems may not fit into cost sensitive metro-access networks. It is important to keep capital (CAPEX) and operational expenditures (OPEX) as low as possible, although flexibility and the possibility to change the provided bandwidth on customer's request are still desired in future access networks. Sliceable transponder for access networks using intensity modulation direct-detection (IMDD) were simulatively evaluated first time by [4].

We demonstrated experimental results for sliceable transponder with NRZ coding, previously in [5]. A 1 Gbit/s baseband signal was sliced in two slices, transmitted over an optical fiber span of up to $25 \mathrm{~km}$, and recovered error-free [5]. Based on these results, we proceed with sliceable transponders and demonstrate simulation and experimental results for a more complex direct modulation format and showed the scalability of this method by increasing the number of used slices.

This paper is organized as followed: Section 2 describes the principle of sliceable transponder. Section 3 reviews and describes the duobinary signaling and explains its advantages. In section 4 and 5 simulation and experimental results of sliceable transponder for $1 \mathrm{Gbit} / \mathrm{s}$ and $10 \mathrm{Gbit} / \mathrm{s}$ data transmission speeds are shown. Section 6 gives an overview on possible applications for sliceable transponders. Finally, we end with our conclusion.

*chwag@fotonik.dtu.dk; phone +45 4525-6352; fax +45 4593-6581; www.fotonik.dtu.dk 


\section{PRINCIPLE OF SLICEABLE TRANSPONDERS}

Basically, sliceable transponders divide a wide bandwidth signal into smaller fractions (slices), transmitting these slices, and stitch all slices together at the receiver side to recover the origin data. In this approach a sliceable transponder contains a digital signal processing (DSP) unit, which realizing slicing and stitching back operation. Figure 1 shows the principle downstream scheme of a sliceable transponder from the service provider (optical line terminal (OLT)) to an end user (optical network unit (ONU)). At the OLT side a DSP unit performs a fast Fourier transformation (FFT) of the original signal and converts it from time domain to frequency domain. In frequency domain $\mathrm{N}$ rectangular digital filters are used to split the spectrum of the origin data signal in $\mathrm{N}$ slices. In Figure 1 only 2 slices are shown, but signal slicing technique is not limited by two slices only. By adjusting the number of slices the bandwidth of each slice can be matched to the transmitter and receiver bandwidth. The necessary transmitter bandwidth for each slice can be calculated by the input signal bandwidth divided by the number of slices $\mathrm{N}$. Next, each slice is down-converted to baseband, except the first one, because it is already in baseband. The different slices can be transmitted over the optical distribution network (ODN). Note, the slices can be transmitted by different media such as fiber or copper cables. Wireless transmission should be possible also. Two transmission schemes over the ODN are possible. First transmission scheme is time division multiplexing (TDM), which allows a serial slice transmission on a single wavelength (Figure 1a). Second, Wavelength division multiplexing (WDM) allows a parallel slice transmission via different wavelengths (Figure 1b). At the ONU side the slicing process is reverted. Each slice is up-converted to its origin frequency range and all slices are stitched back to restore the origin waveform.

Due to the use of a DSP sliceable transponder are not limited to non-return-to-zero (NRZ) signals. All digital modulation formats can be implemented. In metro-access networks only intensity modulation formats are used due to cost sensitivity of such networks. However, using more complex modulation formats like pulse amplitude modulation (M-PAM) or duobinary at least doubles the amount of transmitted data. Our proposed technique fits into the simple and cost sensitive optical access network, due to use of IMDD. The opportunity to adjust the bandwidth by the number of slices and the modulation format shows it is future proofed and robust also.

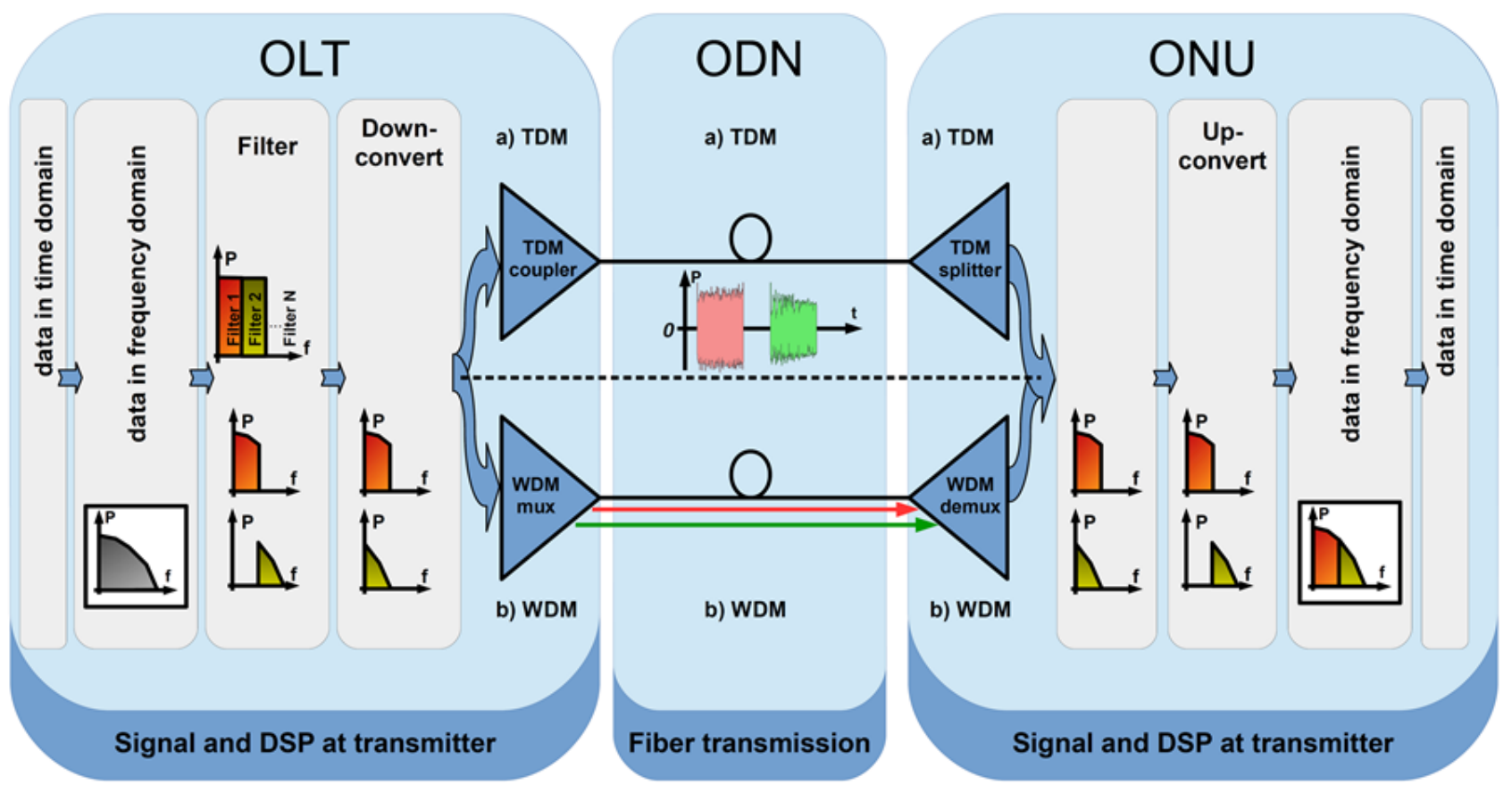

Figure 1. Principle of slicing an input waveform into two slices at the OLT; transmitted over the ODN via (a) TDM or (b) WDM, and reconstruction of the origin waveform at the ONU. 


\section{DUOBINARY GENERATION AND RECOVERY}

Duobinary is an advanced intensity modulation format, which can be detected by simple direct detection and counts to the partial response signaling schemes. Duobinary uses a known amount Inter-Symbol Interference (ISI) to achieve higher spectral efficiencies. Due to the allowed ISI the necessary bandwidth is 0.5 to 0.75 times the bandwidth of a NonReturn-to-Zero (NRZ) signal [6]. A narrower spectrum in frequency domain has the advantage to be more robust against chromatic dispersion (CD) and the equipment bandwidth of used lasers or modulators and photodiodes can be reduced.

Duobinary can be digitally encoded or in fiber-optic transmission systems optical duobinary (ODB) can be generated by using Bessel low-pass filters (LPF). For ODB encoding of a $10 \mathrm{Gbit} / \mathrm{s}$ signal a $3 \mathrm{GHz}$ Bessel LPF can be used for improved receiver sensitivity [7] and for better amplified spontaneous emission (ASE) noise limited performance a 2.8 GHz Bessel LPF can be used [8].

Digitally encoded duobinary was proposed by [9]. The modulation scheme encoded a binary data stream $\mathrm{a}_{\mathrm{n}}$ at first as two different polarization (Equation (1)). In Equation (2) ISI is introduced by the sum of $b_{n}$ and its precursor symbol $b_{n-1}$. As result $\mathrm{c}_{\mathrm{n}}$ has three-levels with ISI $[9,10]$.

$$
\begin{gathered}
\mathrm{b}_{\mathrm{n}}=\left\{\begin{array}{rll}
-1 & \text { for } & a_{n}=0 \\
1 & \text { for } & a_{n}=1
\end{array}\right. \\
\mathrm{c}_{\mathrm{n}}=b_{n}+b_{n-1}=\left\{\begin{array}{cll}
2 & \text { for } & a_{n}=a_{n-1}=1 \\
0 & \text { for } & a_{n} \neq a_{n-1} \\
-2 & \text { for } & a_{n}=a_{n-1}=0
\end{array}\right.
\end{gathered}
$$

The known introduced ISI at the transmitter side can be reverted at the receiver by differential decoding (Equation (3)).

$$
\mathrm{b}_{\mathrm{n}}=c_{n}-b_{n-1}
$$

This encoding and decoding scheme has a crucial disadvantage. A single error will propagate forever in the decoder [6].

To overcome this disadvantage a (differential) precoding $b_{k}$ is required. One possible precoding scheme is using an $\mathrm{X}-\mathrm{OR}$ of the current NRZ bit $\mathrm{a}_{\mathrm{k}}$ and the precursor bit of the precoded signal $\mathrm{b}_{\mathrm{k}}$.

$$
\begin{array}{ll}
\mathrm{b}_{\mathrm{k}}=a_{k} \oplus b_{k-1} & \text { with } \oplus \text { is X-OR } \\
\mathrm{c}_{\mathrm{k}}=b_{k}+b_{k-1} &
\end{array}
$$

Equation (4) describes the digital precoding. $\mathrm{a}_{\mathrm{k}}$ is the k-th bit of the original NRZ signal, which is X-OR linked with the precursor of precoded signal. $b_{k}$ contains still the values zero and one only. For the first bit an additional zero or one can be used. In Equation (5) the k-th bit and its precursor are summed up to generate a three-level duobinary signal, which is transmitted over the ODN. Table 1 shows the different encoding results described above.

Table 1. Example of digital encoded duobinary signal with X-OR precoding.

\begin{tabular}{|c|c|c|c|c|c|c|c|c|c|c|c|c|c|c|c|}
\hline Bit & $\mathbf{0}$ & $\mathbf{1}$ & $\mathbf{2}$ & $\mathbf{3}$ & $\mathbf{4}$ & $\mathbf{5}$ & $\mathbf{6}$ & $\mathbf{7}$ & $\mathbf{8}$ & $\mathbf{9}$ & $\mathbf{1 0}$ & $\mathbf{1 1}$ & $\mathbf{1 2}$ & $\mathbf{1 3}$ & $\mathbf{1 4}$ \\
\hline $\mathrm{a}_{\mathrm{k}}$ & & 0 & 1 & 0 & 1 & 1 & 0 & 1 & 1 & 1 & 0 & 0 & 0 & 1 & 1 \\
\hline $\mathrm{b}_{\mathrm{k}}$ & 0 & 0 & 1 & 1 & 0 & 1 & 1 & 0 & 1 & 0 & 0 & 0 & 0 & 1 & 0 \\
\hline $\mathrm{c}_{\mathrm{k}}$ & & 0 & 1 & 2 & 1 & 1 & 2 & 1 & 1 & 1 & 0 & 0 & 0 & 1 & 1 \\
\hline
\end{tabular}

On the receiver side, a photodiode detects the three-level encoded duobinary signal. The original NRZ signal can be estimated straightforward by a modulo 2 operation directly from $\mathrm{c}_{\mathrm{k}}$, which is described in Equation (6) 


$$
\mathrm{a}_{\mathrm{k}} \approx c_{k} \bmod 2
$$

This coding and decoding scheme is simple to implement in a DSP and avoids signal degeneration due to error propagation, because the estimation does only depend on the current bit and not on the former bit [11].

Another advantage of duobinary is the reduced optical bandwidth allocation. The sub-carrier spacing in a WDM system can be reduced to approx. 0.8 times the Baud rate, which leads to a sub-Nyquist channel spacing [12]. This is especially interesting for future flexgrid networks with software defined networking (SDN) control to enhance the spectral efficiency.

\section{SIMULATION OF SLICEABLE TRANSPONDER}

\subsection{Simulation of duobinary encoded $1 \mathrm{Gbit} / \mathrm{s}$ NRZ signal sliced in 2 slices}

First a $1 \mathrm{Gbit} / \mathrm{s}$ NRZ pseudo-random binary sequence (PRBS) is created. This NRZ signal is encoded as duobinary signal after Equation (4) and (5). Equation (5) was modified to

$$
c_{\mathrm{k}}=b_{k}+b_{k-1}-1
$$

Equation (7) leads to differential encoded duobinary with the levels $+1,0$, and -1 . This coding scheme suppresses the direct component. However, when the signal is recovered with Equation (6) the NRZ signal is inverted.

After an FFT the spectrum of the NRZ-signal and the duobinary signal is shown in Figure 2(a) and 2(b), respectively.
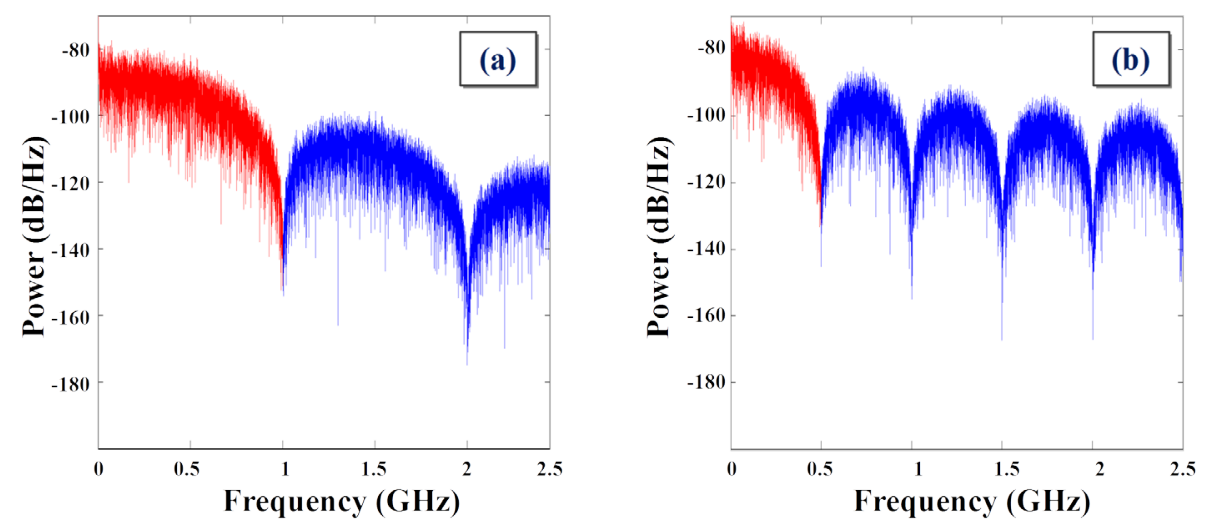

Figure 2. Spectrum after FFT of (a) origin $1 \mathrm{Gbit} / \mathrm{s}$ NRZ-signal and (b) duobinary encoded $1 \mathrm{Gbit} / \mathrm{s}$ signal. Blue: full spectrum; red: filtered spectrum of original signal

The blue spectrum, in both cases, is the full spectrum after FFT. Due to the time limited signal some higher orders are also shown. For further processing the first order, red curve in Figure 2 (a) (up to $1 \mathrm{GHz}$ in frequency) and 2 (b) (up to $0.5 \mathrm{GHz}$ in frequency), is used only and is filtered by applying a rectangular filter in the DSP. The bandwidth reduction of the duobinary encoded signal, which is one half of the 1 Gbit/s NRZ-signal bandwidth is also shown in Figure 2.

Next, the filtered duobinary spectrum is sliced in two slices with $250 \mathrm{MHz}$ bandwidth each and the second slice is downconverted to baseband (see Figure 3). Moving the second slice to baseband (Fig. 3(d)) allows the transmission of this slice via low bandwidth equipment and therefore, the whole signal can be transmitted by using only half the bandwidth of original signal's bandwidth. Thereby, these slices are ready to be transmitted in time domain after an inverse FFT (iFFT).

On the receiver side (ONU) the time domain signals are captured. To reverse the slicing process, slices are transformed to frequency domain, where the second slice is shifted to its origin frequency allocation. 
(a)

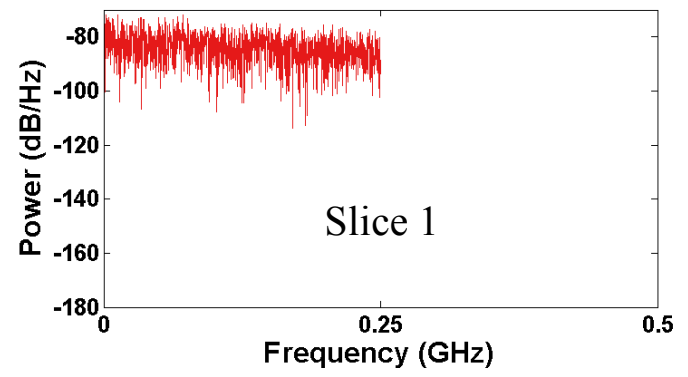

(c)

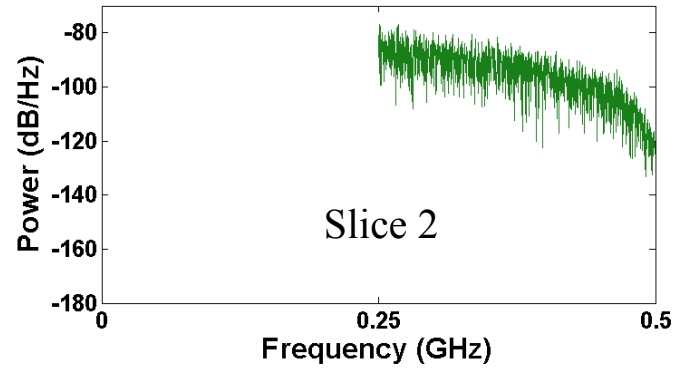

(b)

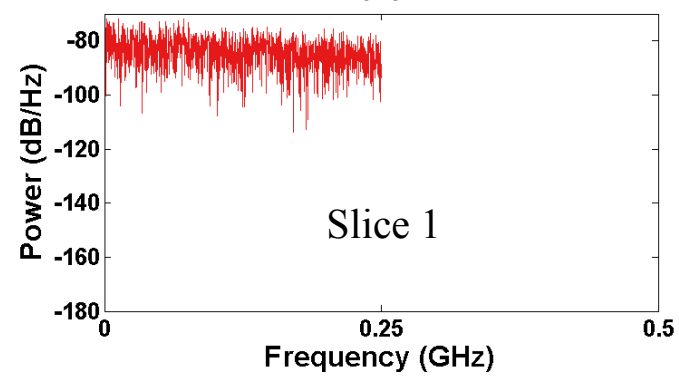

(d)

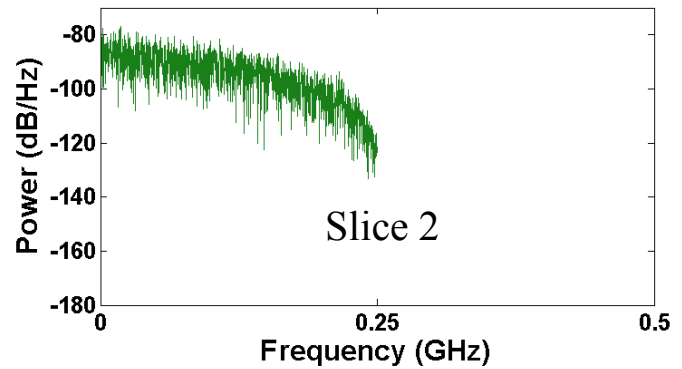

Figure 3. Duobinary encoded spectrum. (a) spectrum of slice 1 in baseband; (b) spectrum of slice 1 not moved; (c) spectrum of slice 2 at its origin frequency allocation; d) spectrum of slice 2 moved to baseband.

After all slices are at the origin frequency, they are concatenated to recover the origin frequency spectrum of initial 1 Gbit/s duobinary signal. For performance evaluation the recovered spectrum is transformed to time domain and eye diagram as well as time signal of the duobinary encoded signal are compared with the signal before spectrum slicing operation.

Figure 4. Comparison of time domain signal (a) after duobinary encoding filtered with $500 \mathrm{MHz}$; (b) after slicing and stitching back; (c) eye diagram of the duobinary signal with $500 \mathrm{MHz}$ filter; (d) eye diagram after slicing and stitching back. 
Figure 4 (a) and (b) shows the time domain signal of the duobinary encoded signal as well as sliced and stitched back signal, respectively. There are almost no differences in the waveform. Figure 4 (c) and (d) shows the eye diagrams before and after slicing operation again. Also, the eye diagrams are similar. Hence, sliceable transponders are working for a $1 \mathrm{Gbit} / \mathrm{s}$ NRZ-signal, encoded as duobinary signaling and sliced in two $250 \mathrm{MHz}$ slices from the DSP point of view.

\subsection{Simulation of duobinary encoded $10 \mathrm{Gbit} / \mathrm{s} \mathrm{NRZ}$ signal sliced in 10 slices}

For proofing the scalability of this concept a $10 \mathrm{Gbit} / \mathrm{s}$ NRZ signal is also encoded as duobinary, as shown previously for the $1 \mathrm{Gbit} / \mathrm{s}$ encoding. The resulting bandwidth for the $10 \mathrm{Gbit} / \mathrm{s} \mathrm{NRZ}$ signal encoded as duobinary is $5 \mathrm{GHz}$, shown in Figure $5 \mathrm{a}$ ) and b), respectively. As said in subsection 4.1, the blue spectrum shows higher order due to the FFT of a time limited signal. The red curve is filtered by a rectangular filter and is processed further. The duobinary coding scheme is similar as described in subsection 4.1.
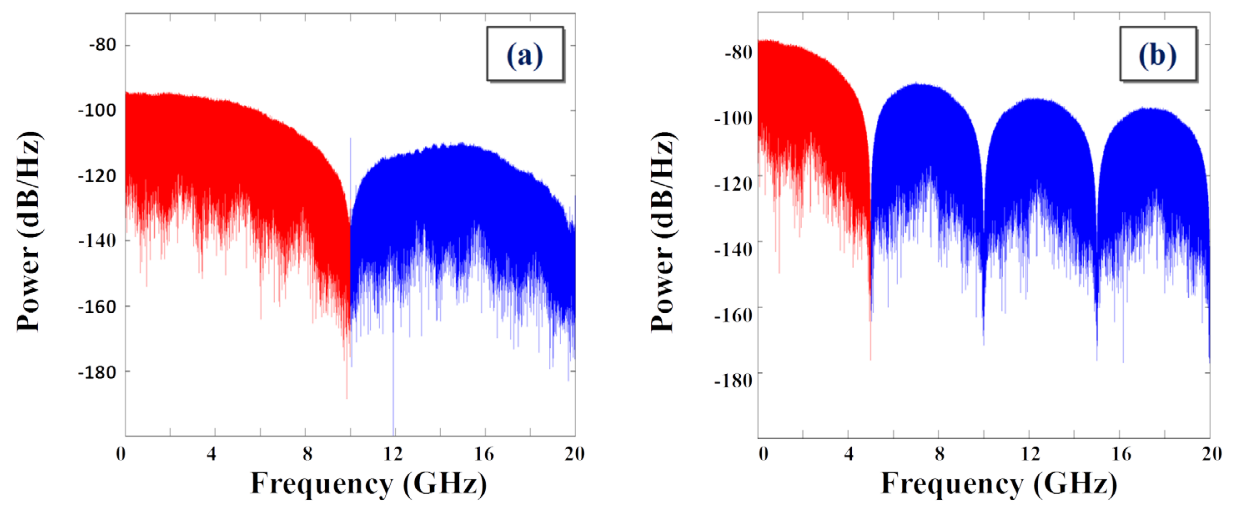

Figure 5. Spectrum after FFT of a) $10 \mathrm{Gbit} / \mathrm{s}$ NRZ-signal and b) this signal encoded as duobinary; blue: whole spectrum after FFT; red: rectangular filtered spectrum

The red spectrum in Figure 5 (b) (up to $5 \mathrm{GHz}$ in frequency) is sliced in 10 slices with $500 \mathrm{MHz}$ bandwidth each. Slices in passband are down-converted to baseband, as shown in Figure 6.
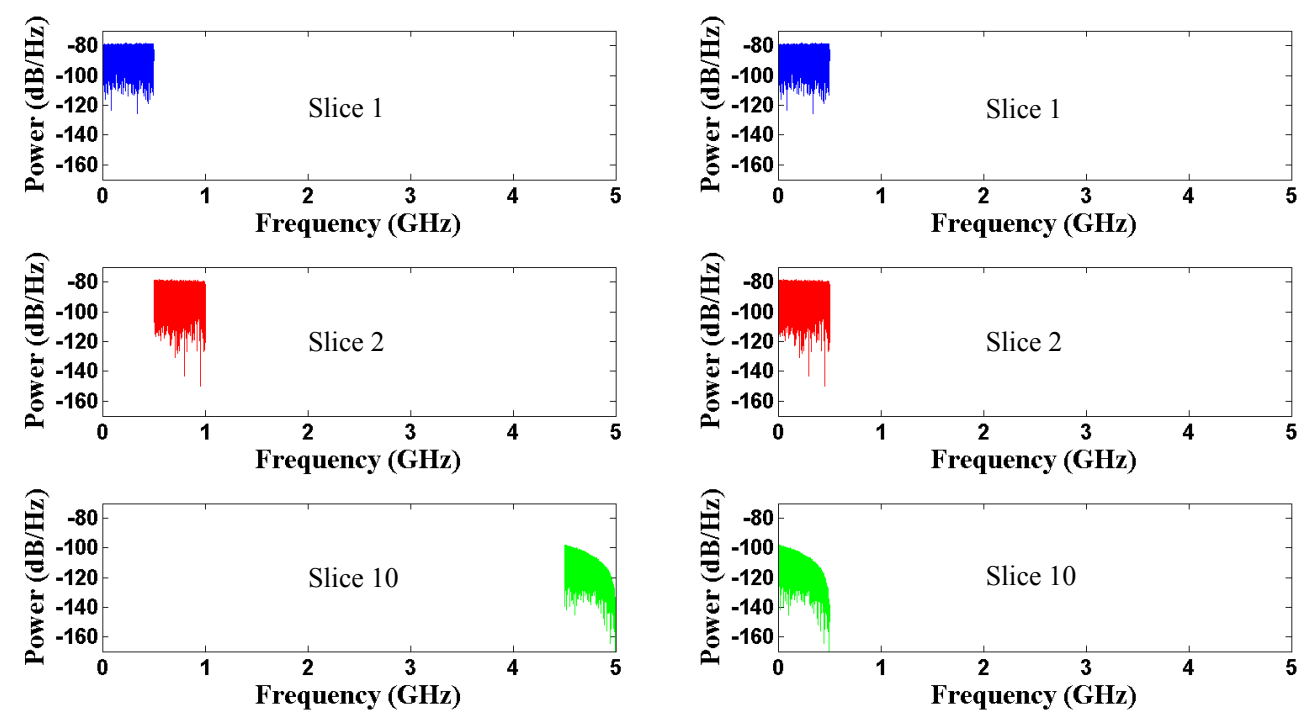

Figure 6. 10Gbit/s NRZ signal duobinary encoded in 10 slices: (a) slice 1 in baseband, (b) slice 2 in passband, (c) slice 10 in passband, (d) slice 1 in baseband and not moved, (e) slice 2 moved to baseband and (f) slice 10 moved to baseband. 
All slices in baseband are transformed to time domain. At the receiver side on each slice a FFT operation is performed to transform the slice into frequency domain, where the slices are moved to their origin frequency allocation and are concatenated to create the origin spectrum. To ensure a $10 \mathrm{Gbit} / \mathrm{s}$ duobinary signal sliced in 10 slices can be restored correctly, the time domain waveform and eye diagram are compared with the origins before slicing (Figure 7).

Figure 7. Comparison of time domain signal: (a) after duobinary encoding filtered with $5 \mathrm{GHz}$ rectangular filter; (b) after slicing and stitching back; (c) eye diagram of the duobinary signal with $500 \mathrm{MHz}$ Filter; (d) eye diagram after slicing and stitching back.

It can be seen from Figure 7 that there are only minor differences between the sliced-stitched signal (Fig. 7(b) and 7(d)) and the origin signal (Fig. 7(a) and 7(c)). Hence, a sliceable transponder for $10 \mathrm{Gbit} / \mathrm{s}$ links with up to ten slices and stitching back should be possible.

\section{EXPERIMENTAL SETUP AND RESULTS}

\subsection{Experimental setup}

The measurement setup is the same for the $1 \mathrm{Gbit} / \mathrm{s}$ and $10 \mathrm{Gbit} / \mathrm{s}$ transmission experiments and is shown in Figure 8. A $2^{15}-1$ long PRBS pattern is loaded into a DSP. The DSP performs the slicing process as described in section 4 . After slicing and down-conversion to baseband each slice is transformed to time domain and all slices are concatenated with a guard band between them for TDM transmission. The concatenated waveform is sent to an arbitrary waveform generator (AWG) with ca. $500 \mathrm{MHz}$ analog bandwidth and $1.25 \mathrm{GS} / \mathrm{s}$ sampling rate. The slices, described in section 4, are matched to a maximum bandwidth of $500 \mathrm{MHz}$. The output of the AWG is combined with a DC-voltage without amplifier in a bias-tee to drive the electro-absorption modulator (EAM) section of an integrated distributed feedback (DFB)-EAM laser. The laser section is driven at DC-bias current of $55 \mathrm{~mA}$. At this bias current the DFB laser emits at $1551.2 \mathrm{~nm}$ wavelength 


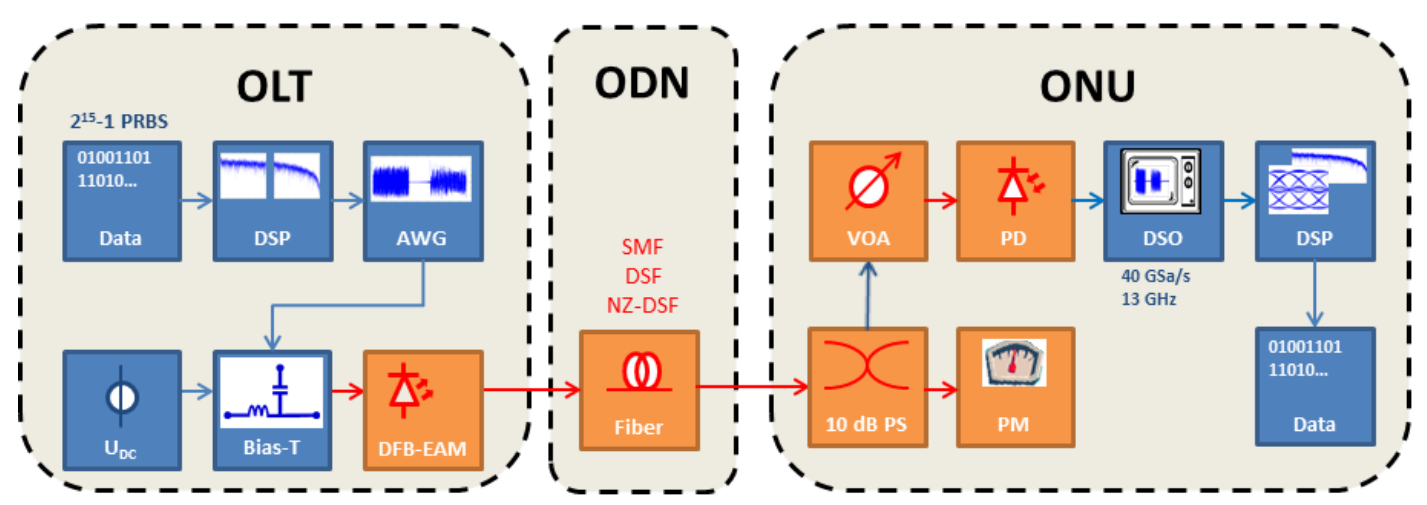

Figure 8. Measurement setup for sliceable transponder transmission experiments.

and $-0.9 \mathrm{dBm}$ output power. The modulated optical signal is launched into an ODN, represented via optical fibers with lengths up to $40 \mathrm{~km}$. Relevant access network fibers are tested: standard single mode fiber (SMF), dispersion shifted fiber (DSF) and non-zero dispersion-shifted fiber (NZ-DSF).

At the ONU, after transmission, a $10 \mathrm{~dB}$ power splitter divides the signal to a power meter (PM) with $10 \mathrm{~dB}$ losses for power monitoring and a linear variable optical attenuator (VOA) with $3 \mathrm{~dB}$ insertion loss at $1550 \mathrm{~nm}$. The VOA optical output signal is converted to an electrical signal by a photodiode (PD) with $10 \mathrm{GHz}$ bandwidth. The electrical signal is recorded by a digital storage oscilloscope (DSO) with $13 \mathrm{GHz}$ bandwidth and $40 \mathrm{GS} / \mathrm{s}$ sampling rate. An offline DSP restores the $1 \mathrm{Gbit} / \mathrm{s}$ or $10 \mathrm{Gbit} / \mathrm{s}$ waveform and measures the bit error rate (BER).

\subsection{Experimental results for $1 \mathrm{Gbit} / \mathrm{s}$ signal sliced in 2 slices}

For proof of sliceable transponder principle, the received and recovered time domain waveform (Figure 9 (b)) and eye diagram (Figure 9 (d)) after optical back-to-back (B2B) are compared with the electrical input signal of the AWG (Figure 9 (a)) and its eye diagram (Figure 9 (c)). Comparing these waveforms only small differences are visible.

Figure 9. Comparison of a 1 Gbit/s duobinary encoded signal: (a) initial waveform; (b) 2 times sliced and recovered waveform after B2B transmission; (c) eye diagram of the initial waveform; (d) eye diagram of the 2 times slices and recovered waveform after $\mathrm{B} 2 \mathrm{~B}$ transmission 
For the recovered eye diagram a clear eye opening is observed, hence, an error free transmission should be possible. For evaluation of the transmission performance bit error measurements are done for different fibers and transmission lengths of $10 \mathrm{~km}, 20 \mathrm{~km}$, and $40 \mathrm{~km}$. Figure 10 shows an post $7 \%$ overhead forward error correction (FEC) error free transmission at received powers of $-18.5 \mathrm{dBm}$, roughly. Note, the results for $10 \mathrm{~km}$ and $20 \mathrm{~km}$ are not shown in Figure 10 due to their similarity to the shown results at $40 \mathrm{~km}$ transmission distance.

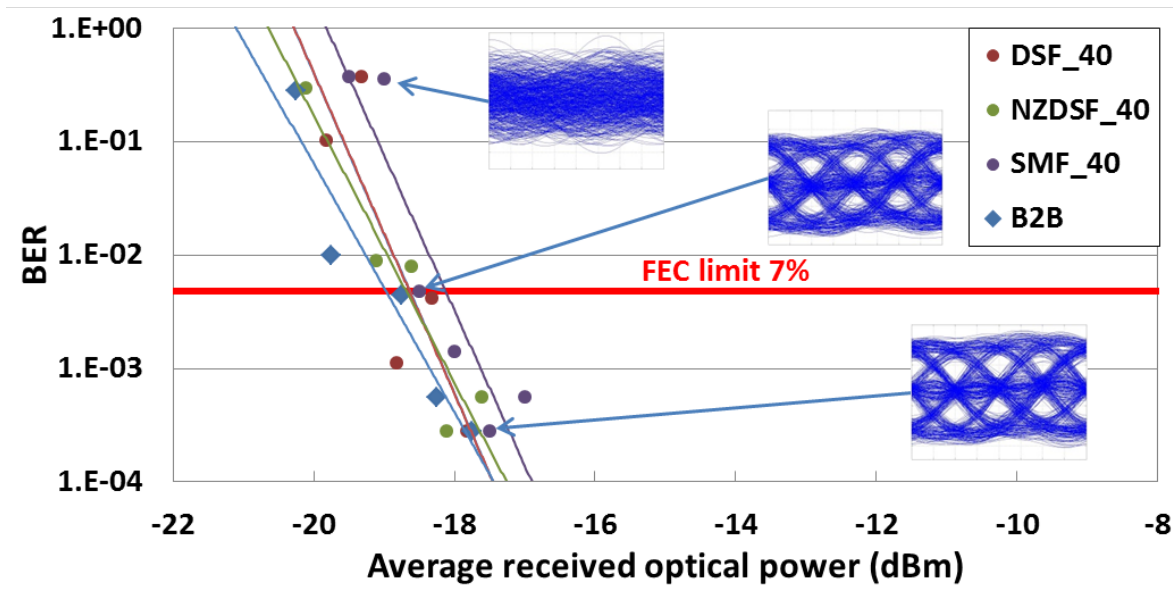

Figure 10. BER Curve for different fibers with lengths up to $40 \mathrm{~km}$

\subsection{Experimental results for $10 \mathrm{Gbit} / \mathrm{s}$ signal sliced in 10 slices}

Due to the good performance of $1 \mathrm{Gbit} / \mathrm{s}$ signal sliced in two slices we decided to go further and sliced $10 \mathrm{Gbit} / \mathrm{s}$ duobinary encoded signal in 10 separate slices, transmitted them and stitched back to restore original waveform. This proofs the principle of sliceable transponders for higher bitrates, as well as the scalability of the number of slices. All 10 slices are transmitted via TDM, as described above, and have a bandwidth of $500 \mathrm{MHz}$ each. In contrast to Figure 10 the bit error curves for the $10 \mathrm{Gbit} / \mathrm{s} 10$ times sliced duobinary encoded signal for $10 \mathrm{~km}$ are also shown in Figure 11 . The $7 \%$ overhead FEC limit is achieved for a received detector power of $-18.5 \mathrm{dBm}$, like for the 2 slices transmission.

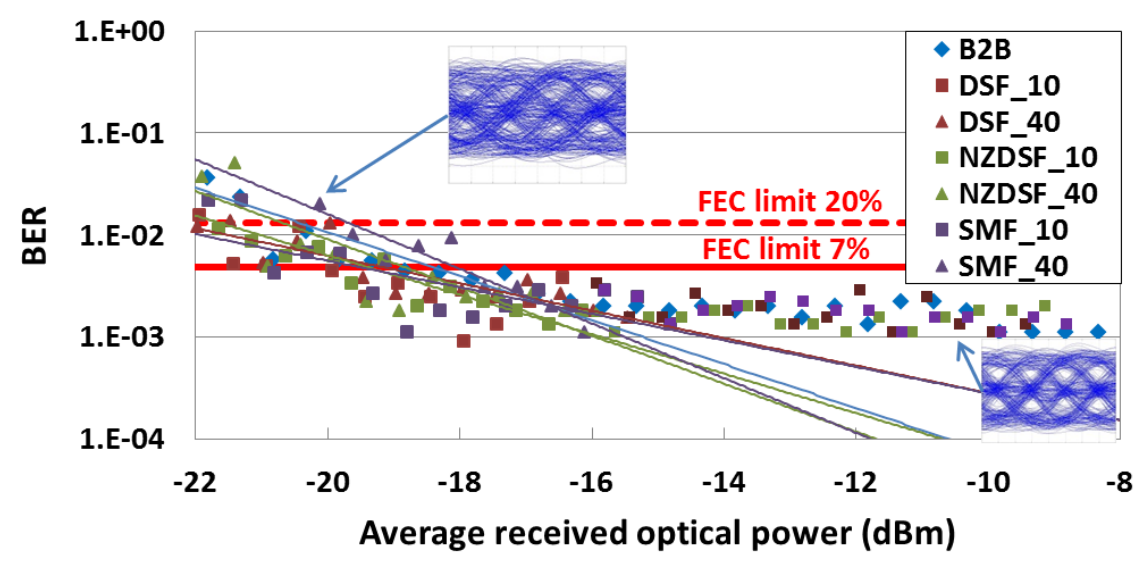

Figure 11. BER performance of restored $10 \mathrm{Gbit} / \mathrm{s}$ duobinary encoded signal formed from 10 separate transmitted and received slices.

However, for $-17 \mathrm{dBm}$ and higher received powers an error floor is visible for $10 \mathrm{~km}$ as well as for $40 \mathrm{~km}$ transmission distance and for all tested types of fiber. The error floor is also shown for B2B measurement. Therefore, this error floor is not related to dispersion or other linear or nonlinear fiber effects. It is assumed that the error floor is related to a nonideal stitching back process of 10 separate received slices. The complexity and sensitivity of spectrum-sliced transponders scales with number of used of slices. In real systems this is avoidable by commonly used framing. Hence, 
sliceable transponder technique is applicable for higher data rates and the number of slices can be scaled to fit the signal bandwidth to the used transmitter and receiver bandwidth.

\section{APPLICATIONS OF SPECTRUM SLICING TECHNIQUE}

Signal slicing technique can be used in sliceable transponders for different applications. They can be divided in non-real time and real time applications.

First, non-real time applications are described more detailed. For non-real time applications sliceable transponder uses TDM transmission scheme. By adding DSP complexity signal slicing technique allows the reuse of low bandwidth equipment for transmitting wider bandwidth signals. This may result in power savings due to reduced bandwidth efforts of the AWG device. However, due to faster input signals than they are transmitted, probably a buffer is necessary to be added. On the other hand, when a storage space is available, the bandwidth could be increased on user's request. This scenario is feasible for example for observation cameras.

Second, real time applications use WDM transmission scheme. Each slice is transmitted over its own wavelength. Therefore, a $10 \mathrm{Gbit} / \mathrm{s}$ signal could be sliced in 10 slices and transmitted over 10 wavelengths, where each laser has a bandwidth of $1 \mathrm{GHz}$ for NRZ signaling or $500 \mathrm{MHz}$ for a duobinary signaling. This transmission scheme occupies more fiber resources. However, this is a common technique to increase the data transmission rate. For example $100 \mathrm{Gbit} / \mathrm{s}$ are usually achieved by multiplexing 4 times $25 \mathrm{Gbit} / \mathrm{s}$ signals. On the other hand, it is not necessary to buy new equipment for each network upgrade. Instead of this, already existing opto-electrical equipment can be upgraded by using spectrum slicing technique.

Last, it should be pointed that signal slicing technique can help to increase the network security. Each slice contains only a small part of the whole bit stream. Without all other slices this small part of information is useless and cannot be restored. Slices can be transmitted on different routes or media. Hence, if an Eve (eavesdropper), a passive attacker, is present on a line it cannot reconstruct the information (initial transmitted waveform).

\section{CONCLUSION}

We reported on sliceable transponder using signal slicing and stitching back technique. Simulation and experimental results show a clear eye opening and post-FEC error free transmission with $7 \%$ overhead after $40 \mathrm{~km}$ fiber span for all commonly used fiber types in optical access networks. The scalability of sliceable transponder is demonstrated by successful simulation and transmission experiments of a $10 \mathrm{Gbit} / \mathrm{s}$ duobinary encoded signal sliced in 10 slices and stitched back after transmission over $40 \mathrm{~km}$ long SMF, NZ-DSF, and DSF fiber spans. For a duobinary signal in 10 slices an error floor is visible due to minor mismatch between received slices. It is assumed that this error floor can be avoided in framed transmission systems. Finally, some possible applications are explained.

Implementation of sliceable transponder adds a degree of freedom, which allows the transmission of high bandwidth signals over much lower bandwidth equipment. This can help to overcome the electronic bottleneck, enable flexible bandwidth allocation on demand, allows reuse of opto-electrical equipment during network upgrades and it can be used for security applications.

\section{ACKNOWLEDGEMENTS}

This work has been supported by the Marie Curie ABACUS project. The authors would like to acknowledge Lau Frejstrup Suhr and Robert Borkowski for their support regarding the DSP part. J.J. Vegas Olmos wishes to acknowledge EU IPHOBAC-NG and Marie Curie FENDOI for partly funding his research.

\section{REFERENCES}

[1] Geisler, D. J., Fontaine, N. K., Scott, R. P., He, T., Paraschis, L., Gerstel, O., Heritage, J. P. and Yoo, S. J. B., "Bandwidth Scalable, Coherent Transmitter Based on Parallel Synthesis of Multiple Spectral Slices," Proc. OFC 2011, OTuE3 (2011). 
[2] Geisler, D. J., Fontaine, N. K., Scott, R. P and Yoo, S. J. B., "Demonstration of a Flexible Bandwidth Optical Transmitter/Receiver System Scalable to Terahertz Bandwidths,” IEEE Photon. J., vol.3, no.6, 1013 - 1022 , (2011)

[3] Fontaine, N. K., Geisler, D. J., Scott, R. P., He, T., Heritage, J. P. and Yoo, S. J. B., "Demonstration of highfidelity dynamic optical arbitrary waveform generation," OPTICS EXPRESS 22989 (2011).

[4] Spolitis, S., Vegas Olmos, J. J., Bobrovs, V., Ivanovs, G. and Monroy, I. T.,"A Novel Approach for Transmission of 56 Gbit/s NRZ Signal in Access Network Using Spectrum Slicing Technique," in ACP/IPOC, paper AF4D.2, (2013).

[5] Spolitis, S., Wagner, C., Vegas Olmos, J. J., Bobrovs, V., Ivanovs, G. and Monroy, I. T., "Experimental demonstration of a scalable sliceable transceiver for optical access network," ACP/IPOC, 2014.

[6] Grobe, K. and Eiselt, M., [Wavelength Division Multiplex: A Practical Engineering Guide], John Wiley \& Sons, Hoboken, New Jersey, 224-228 (2014).

[7] Lu, Y. C., Wei, C. C., Chen, J., Tsao, C., Chi, S., Feng, K. M., Yeh, P. C., Huang, T. Y. and Chang, C. C., "2.5 $\mathrm{dB}$ sensitivity improvement by optimizing the driving voltage of an MZM and electrical filter bandwidth of optical duobinary transmission systems," in Optical Fiber Communication Conference, Optical Society of America, paper JThB42 (2006).

[8] Lyubomirsky, I. and Chien, C. C., "Ideal duobinary generating filter for optically amplified systems," IEEE Photon. Technol. Lett. 18(4), 598-600 (2006).

[9] Lender, A., "the Duobinary Technique for High-speed Data Transmission," IEEE Trans. Commun. Electron., vol. CE-82, no. 66, 214-218, (1963).

[10] Pasupathy, A., "Correlative Coding: A Bandwidth-Efficient Signaling scheme," IEEE COMMUNICATIONS SOCIETY MAGAZINE, 4-11 (1977)

[11] Vegas Olmos, J. J., Suhr, L. F., Li, B. and Monroy, I. T., "Five-level polybinary signaling for 10 Gbps data transmission systems," in Proc. OPTICS EXPRESS, 20417-20422 (2013).

[12] Grobe, K., Grießer, H., Autenrieth, A. and Elbers, J.-P., "Software-Defined Optics as Solution for NextGeneration Inter-Data-Center Ultra-High-Speed DWDM Transport," Terena networking conference (2012). 